\title{
Functional abolition of carotid body activity restores insulin action and glucose homeostasis in rats: key roles for visceral adipose tissue and the liver
}

\author{
Joana F. Sacramento ${ }^{1}$ Maria J. Ribeiro ${ }^{1}$. Tiago Rodrigues ${ }^{2} \cdot$ Elena Olea $^{3}$. \\ Bernardete F. Melo ${ }^{1}$. Maria P. Guarino ${ }^{1,4}$ - Rui Fonseca-Pinto ${ }^{5,6}$. \\ Cristiana R. Ferreira ${ }^{1}$. Joana Coelho ${ }^{1}$ - Ana Obeso ${ }^{3} \cdot$ Raquel Seiça $^{2}$ • \\ Paulo Matafome ${ }^{2,7} \cdot$ Sílvia V. Conde ${ }^{1}$
}

Received: 28 June 2016 / Accepted: 13 September 2016 /Published online: 16 October 2016

(C) Springer-Verlag Berlin Heidelberg 2016

\begin{abstract}
Aims/hypothesis We recently described that carotid body (CB) over-activation is involved in the aetiology of insulin resistance and arterial hypertension in animal models of the metabolic syndrome. Additionally, we have demonstrated that $\mathrm{CB}$ activity is increased in animal models of insulin resistance, and that carotid sinus nerve (CSN) resection prevents the development of insulin resistance and arterial hypertension induced by highenergy diets. Here, we tested whether the functional abolition of CB by CSN transection would reverse pre-established insulin resistance, dyslipidaemia, obesity, autonomic dysfunction and hypertension in animal models of the metabolic syndrome. The effect of CSN resection on insulin signalling pathways and tissue-specific glucose uptake was evaluated in skeletal muscle, adipose tissue and liver.

Methods Experiments were performed in male Wistar rats submitted to two high-energy diets: a high-fat diet, representing a model of insulin resistance, hypertension and
\end{abstract}

Electronic supplementary material The online version of this article (doi:10.1007/s00125-016-4133-y) contains peer-reviewed but unedited supplementary material, which is available to authorised users.

\section{Sílvia V. Conde}

silvia.conde@fcm.unl.pt

1 Centro Estudos Doenças Crónicas (CEDOC), Faculdade Ciências Médicas, NOVA Medical School, Universidade Nova de Lisboa, Rua Camara Pestana, 6-6a, Edificio II, piso 3, 1150-082 Lisboa, Portugal

2 Laboratório de Fisiologia, Instituto Biomédico de Investigação de Luz e Imagem (IBILI), Faculdade de Medicina, Universidade de Coimbra, Coimbra, Portugal

3 Departamento de Bioquímica y Biología Molecular y Fisiología, Universidad de Valladolid, Facultad de Medicina. Instituto de Biología y Genética Molecular, Consejo Superior de Investigaciones obesity, and a high-sucrose diet, representing a lean model of insulin resistance and hypertension. Half of each group was submitted to chronic bilateral resection of the CSN. Age-matched control rats were also used.

Results CSN resection normalised systemic sympathetic nervous system activity and reversed weight gain induced by high-energy diets. It also normalised plasma glucose and insulin levels, insulin sensitivity lipid profile, arterial pressure and endothelial function by improving glucose uptake by the liver and perienteric adipose tissue.

Conclusions/interpretation We concluded that functional abolition of CB activity restores insulin sensitivity and glucose homeostasis by positively affecting insulin signalling pathways in visceral adipose tissue and liver.

Keywords Adipose tissue - Carotid sinus nerve · Glucose homeostasis $\cdot$ Insulin sensitivity $\cdot$ Liver

Científicas (CSIC), Instituto de Salud Carlos III (ISCIII), Valladolid, España

4 Unidade de Investigação em Saúde (UIS), Escola Superior de Saúde de Leiria, Instituto Politécnico de Leiria, Leiria, Portugal

5 Escola Superior de Tecnologia e Gestão, Instituto Politécnico de Leiria, Leiria, Portugal

6 Instituto de Telecomunicações, Leiria, Portugal

7 Instituto Politécnico de Coimbra, Escola Superior de Tecnologia da Saúde (ESTeSC), Departmento de Ciências Complementares, Coimbra, Portugal 


$\begin{array}{ll}\text { Abbreviations } \\ \mathrm{CB} & \text { Carotid body } \\ \mathrm{CSN} & \text { Carotid sinus nerve } \\ \mathrm{HF} & \text { High-fat diet-fed } \\ \mathrm{HSu} & \text { High-sucrose diet-fed } \\ \mathrm{IR} & \text { Insulin resistance } \\ \mathrm{ITT} & \text { Insulin tolerance test } \\ K_{\mathrm{ITT}} & \text { Constant of the insulin tolerance test } \\ \mathrm{Rg}^{\prime} & \text { Glucose metabolic index }\end{array}$

\section{Introduction}

Carotid bodies (CBs) are peripheral chemoreceptors that classically sense hypoxia, hypercapnia and acidosis, responding via increased action potential frequency in their sensory nerve, the carotid sinus nerve (CSN). CSN activity is integrated in the brainstem to induce respiratory responses, aimed primarily at normalising blood gases via hyperventilation [1], and regulating blood pressure and cardiac performance via sympathetic nervous system activation [2]. In the last decade, CBs have been described as a major metabolic sensor, implicated in energy homeostasis $[3,4]$. We reported that animal models of the metabolic syndrome displayed abnormal patterns of CB activity [5], associated with hyperinsulinaemia. We demonstrated that insulin stimulates the peripheral chemoreceptors in CBs, crucial for triggering CB-induced sympathoadrenal overactivity, contributing to the vicious cycle of insulin resistance (IR) and hypertension seen in metabolic disorders [5]. The involvement of CBs in the control of metabolic homeostasis is also supported by clinical data: type 2 diabetes patients who underwent functional suppression of CB activity (via hyperbaric oxygen therapy) showed improved glucose tolerance and significantly reduced plasma glucose levels [6-10]. It has also been reported that oxygen therapy significantly decreases systolic blood pressure in both type 2 diabetic and hypertensive patients [11] and improves insulin sensitivity in diabetic patients [8], without changing insulin levels [7]. CBs have recently been considered a novel target for regulating peripheral insulin sensitivity.

We tested whether abolition of CB activity would, with sustainable efficacy, reverse pre-established IR, glucose intolerance, dyslipidaemia and hypertension in animal models of the metabolic syndrome. We also aimed to clarify the mechanisms of action underlying this effect. We hypothesised that CSN transection would improve peripheral insulin action via modification of insulin signalling pathways and tissuespecific glucose uptake in classical insulin-target tissues such as skeletal muscle, adipose tissue and liver. Since the sympathetic nervous system is the natural effector of $\mathrm{CB}$ activation, the reversal potential of CSN denervation on pre-existing sympathetic overactivation was evaluated in animal models of diet-induced metabolic disease.

\section{Methods}

\section{Animals and experimental procedure}

Diets and animal care Experiments were performed in 3-month-old male Wistar rats (200-420 g) obtained from the vivarium of the Faculdade de Ciências Médicas, Universidade Nova de Lisboa, Lisboa, Portugal. After randomisation, the animals were assigned to one of three groups: (1) the highsucrose diet-fed (HSu) group, fed 35\% (wt/vol.) sucrose (PanReac, Madrid, Spain) in drinking water for 28 days representing a lean model of combined IR and hypertension $[5,12]$; (2) the high-fat diet-fed (HF) group, fed a $45 \%$ fat diet ( $45 \%$ fat $+35 \%$ carbohydrate $+20 \%$ protein; Mucedola, Milan, Italy) for 21 days. This model combined obesity, dyslipidaemia, IR and hypertension [13-15]; and (3) an age-matched control group, fed a regular chow diet (see electronic supplementary materials [ESM], reagents and antibodies for details). HSu rats were fed for 28 days because the animals were neither insulin resistant nor hypertensive at 21 days (data not shown). Animals were kept under temperature and humidity control $\left(21 \pm 1^{\circ} \mathrm{C}\right.$; $55 \pm 10 \%$ humidity) with a $12 \mathrm{~h} \mathrm{light} / 12 \mathrm{~h}$ dark cycle and were given ad libitum access to food and water. Body weight was monitored two times per week, and energy and liquid intake were monitored daily. Laboratory care was in accordance with the European Union Directive for Protection of Vertebrates Used for Experimental and Other Scientific Ends (2010/63/ EU). Experimental protocols were approved by the Faculdade de Ciências Médicas Ethics Committee. In subsequent experiments, experimenters were blinded to group assignment and outcome assessment.

CSN transection protocol After evaluation of insulin sensitivity using an insulin tolerance test (ITT) on day 21 for the HF group and day 28 for the HSu group [5, 12], animals were submitted to bilateral CSN transection under ketamine $(30 \mathrm{mg} / \mathrm{kg}) / \mathrm{xylazine}(4 \mathrm{mg} / \mathrm{kg}$ ) anaesthesia and buprenorphine $(10 \mu \mathrm{g} / \mathrm{kg})$ analgesia [5]. The controls for each of the feeding groups were submitted to a sham procedure ( $n=8 / 10$ per group).

Unilateral CSN transection A group of HF rats $(n=8)$ was submitted to unilateral CSN transection to evaluate whether this would sufficiently improve insulin sensitivity.

In vivo analyses After surgery, animals continued their respective high-fat and high-sugar diets during both the recovery period and the remaining experimental period (3 weeks). Fasting glucose, insulin sensitivity and body weight were evaluated weekly during this time. 
Sustained effects of CSN transection A group of sucrose-fed rats $(n=8)$ was monitored for 11 weeks after denervation to assess whether the recovery of metabolic variables would be sustained for $>3$ weeks.

\section{Insulin tolerance test}

Insulin sensitivity was evaluated using an ITT [5] after overnight fasting. Briefly, fasting blood glucose was measured and immediately followed by an insulin bolus $(100 \mathrm{mU} / \mathrm{kg})$, administered via the tail vein. Subsequently, the decline in plasma glucose concentration was measured over a $15 \mathrm{~min}$ period (ESM Methods for full details).

\section{Quantification of serum biomarkers}

Three weeks post-CSN transection, the animals were anaesthetised with pentobarbital (60 mg/kg i.p.), and CSN resection was confirmed by the absence of hypoxia-induced hyperventilation during occlusion of the common carotid artery $[5,16]$. Measurement of mean arterial pressure and blood concentrations of insulin, C-peptide, lipids, nitric oxide and catecholamines was performed as previously described $[5,17$, 18]. Insulin and C-peptide were measured by ELISA kits (Mercodia AB, Uppsala, Sweden). Lipid profile was determined using a RANDOX kit (RANDOX, Porto, Portugal) to determine total cholesterol and triacylglycerols by Trinderbased colourimetric end-point assays, and HDL-cholesterol and LDL-cholesterol by a direct-HDL and direct-LDL clearance method, respectively. Catecholamines were assessed by HPLC with electrochemical detection (see ESM Methods for full details).

\section{In vivo tissue-specific glucose uptake}

The effect of CSN resection on glucose uptake by the liver, skeletal muscle, pancreas and adipose tissue was evaluated in a group of HF rats after an IVGTT with 2-deoxy-D-[1,2- $\left.{ }^{3} \mathrm{H}\right]$ glucose $\left(2-\right.$ deoxy $\left[{ }^{3} \mathrm{H}\right]$ glucose), based on the method by Kraegen et al [19] (see ESM Methods for details).

\section{Western blots}

Skeletal muscle, liver and perienteric adipose tissue were collected and GLUT4, GLUT2, insulin receptor, phosphorylated insulin receptor, Akt and phosphorylated Akt levels were evaluated, as previously described [17, 20] (see ESM Methods for further details, including reagents and antibodies).

\section{Sympathetic activity analysis}

The balance between sympathetic and parasympathetic components of the autonomic nervous system was evaluated by power spectral analysis of heart rate variability [21-24], and by measurement of circulating and adrenal medullary catecholamines [13, 23] (see ESM Methods [Evaluation of spectral modulation of heart rate] for details).

\section{Statistical analysis}

Data were evaluated using GraphPad Prism Software, version 6 (GraphPad Software, La Jolla, CA, USA) and presented as mean values and SEM. The significance of the differences between the mean values was calculated by one- and two-way ANOVA with Bonferroni multiple comparison tests. Differences were considered significant at $p<0.05$.

\section{Results}

\section{Body weight and energy intake}

Animals were randomly allocated to the HSu and HF groups, submitted to the respective diet protocol and then randomly allocated to CSN transection or sham surgery in which the CSN was left intact. The sham procedure did not alter body weight and energy intake in comparison with the respective controls (data not shown). Bilateral CSN resection was confirmed by the absence of increased ventilatory responses to ischaemic-hypoxia during common carotid artery occlusion (data not shown). Bilateral CSN resection and the sham procedure did not significantly modify animal behaviour or energy intake, measured as the average energy intake per day during the 3 weeks after CSN denervation (data not shown).

\section{Bilateral CSN transection restores fasting plasma glucose and insulin sensitivity in animals continuously submitted to high-energy diets}

IR was confirmed before and after surgery by an ITT (data is presented as the constant of the rate of glucose disappearance $\left.\left[K_{\mathrm{ITT}}\right]\right)$. Figure 1 illustrates the effect of CSN transection on fasting plasma glucose and insulin sensitivity in control (Fig. 1a, b), HSu (Fig. 1c, d) and HF (Fig. 1e, f) animals, 3 weeks after surgery. Bilateral CSN ablation did not modify fasting plasma glucose in either control or HF animals (Fig. 1a, e). However, the high-sucrose diet significantly increased fasting plasma glucose, by $49 \%$, whilst physiological glucose levels were restored as early as 1 week after CSN resection (controls, $4.63 \pm 0.1 \mathrm{mmol} / \mathrm{l}$; HSu 1 week after CSN resection, $4.61 \pm 0.2 \mathrm{mmol} / \mathrm{l}$ ) and were sustained in the ensuing 3 weeks (Fig. 1c). Compared to controls, the highsugar and high-fat diets also decreased insulin sensitivity by 47\% (Fig. 1d) and 40\% (Fig. 1f), respectively. One week after $\mathrm{CSN}$ transection, insulin sensitivity was restored in $\mathrm{HSu}$ animals and partially restored in HF animals. Two weeks after 

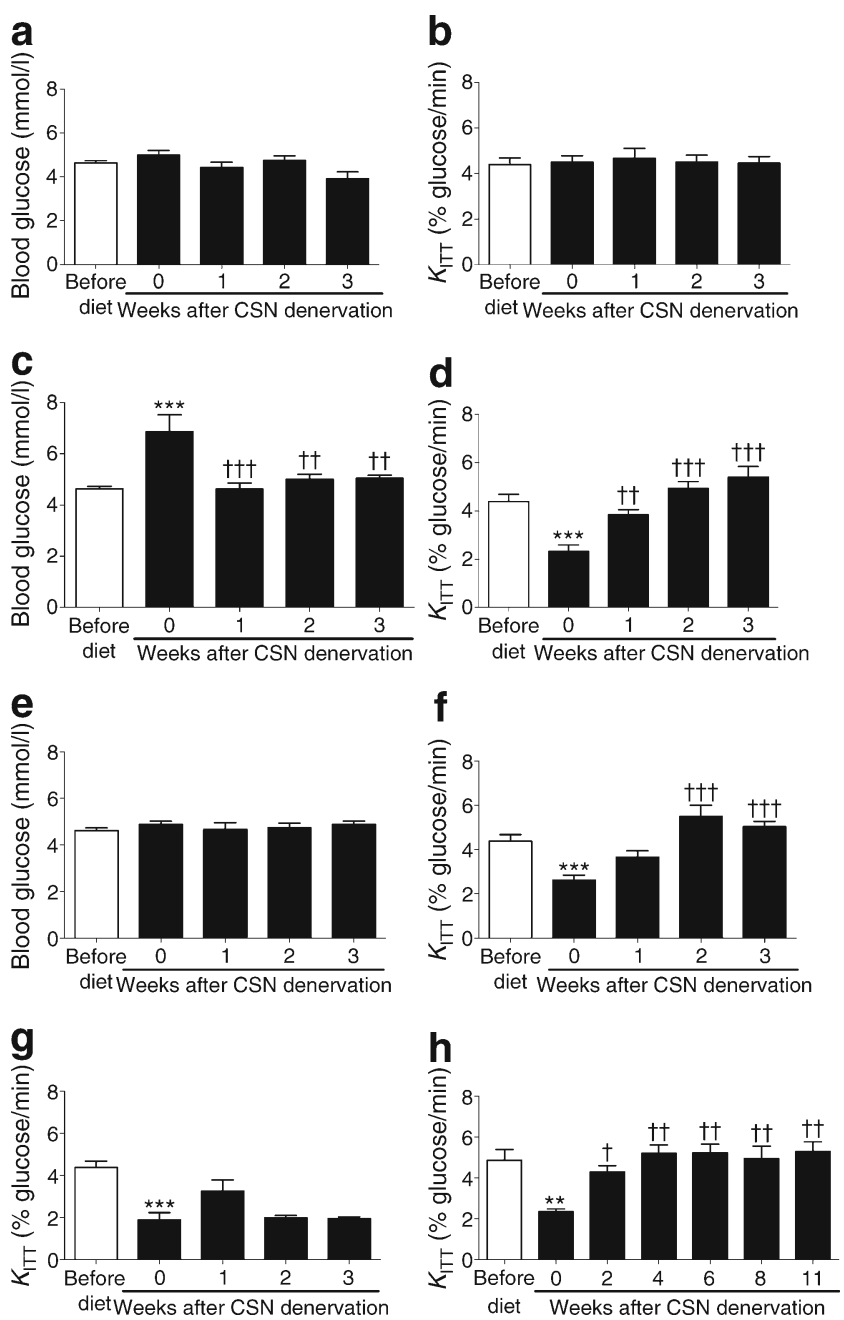

Fig. 1 Effect of CSN transection on (a, c, e) fasting plasma glucose and $(\mathbf{b}, \mathbf{d}, \mathbf{f})$ insulin sensitivity determined by the ITT, expressed as the $K_{\text {ITT }}$ in control, HSu and HF animals, respectively ( $n=8 / 10$ per group). (g) HF animals were submitted to unilateral $\mathrm{CSN}$ resection that was unable to restore insulin sensitivity $(n=8)$. (h) Effect of bilateral CSN transection on insulin sensitivity over 11 weeks, post-surgical CSN ablation in $\mathrm{HSu}$ rats $(n=8)$. White bars, before the respective diets; black bars, immediately before ( 0 weeks) and after CSN denervation. Data are presented as mean \pm SEM. One-way ANOVA with Bonferroni multiple comparison tests; $* * p<0.01, * * * p<0.001$ vs control; ${ }^{\dagger} p<0.05,{ }^{\dagger \dagger} p<0.01,{ }^{\dagger \dagger} p<0.001$, pre vs post CSN resection

CSN transection, insulin sensitivity was totally restored in both animal models, an effect that was sustained until the third week after CSN transection (Fig. 1d, f). Insulin sensitivity in control animals was not affected by CSN transection (Fig. 1b).

To test whether unilateral CSN transection was sufficient to improve insulin sensitivity, unilateral surgical ablation was performed in an independent subgroup of HF rats. Unilateral transection did not completely restore insulin sensitivity to physiological values in HF rats (Fig. 1g). Additionally, insulin sensitivity was monitored in a subgroup of HSu rats for 11 weeks post-surgery to evaluate whether the insulin-sensitising effect induced by bilateral CSN surgical ablation would be maintained.
At the end of the 11-week period, insulin sensitivity was maintained at values similar to those of controls (Fig. 1h).

\section{CSN transection restores plasma insulin and C-peptide in animal models of impaired insulin sensitivity}

Table 1 displays the effect of CSN transection on plasma insulin and C-peptide concentrations. Compared to control animals, HSu and HF animals showed increases in plasma insulin of $123 \%$ and $120 \%$, respectively. C-peptide levels were significantly increased, by $66 \%$ and $82 \%$ in $\mathrm{HSu}$ and HF rats, respectively. CSN transection did not modify either plasma insulin or C-peptide levels in control animals. However, in $\mathrm{HSu}$ and $\mathrm{HF}$ rats, CSN transection restored plasma insulin and C-peptide levels to levels similar to control values, showing that insulin secretion was regulated by CSN ablation (Table 1).

\section{CSN transection improves insulin signalling in skeletal muscle and adipose tissue in animal models of impaired insulin sensitivity}

Figure 2 shows western blot results for key proteins involved in insulin signalling pathways in insulin-sensitive tissues. In the skeletal muscle of HSu and HF animals, insulin receptor levels decreased significantly by $49 \%$ and $48 \%$, respectively (Fig. 2a). Levels were restored in $\mathrm{HSu}$ and HF rats 3 weeks after CSN transection (Fig. 2a). Insulin receptor activity, as assessed by insulin receptor Tyr1361 phosphorylation, also decreased in both HSu and HF groups, by $47 \%$ and $31 \%$, respectively (Fig. 2b). Chronic CSN transection not only restored, but actually increased, insulin receptor phosphorylation in control, $\mathrm{HSu}$ and $\mathrm{HF}$ animals, by $98 \%, 56 \%$ and $98 \%$, respectively, relative to controls (Fig. 2 b). $\mathrm{HSu}$ rats were also observed to have reduced levels (46\% decrease) of GLUT4, which were fully restored 3 weeks after CSN transection, to levels similar to healthy controls (Fig. 2c).

In $\mathrm{HSu}$ and $\mathrm{HF}$ rats, insulin receptor levels were significantly decreased in adipose tissue, by $26 \%$ (Fig. 2d). CSN resection completely restored insulin receptor levels in $\mathrm{HSu}$ animals, but not in the HF, group (Fig. 2d). Similarly, insulin receptor phosphorylation decreased by $35 \%$ and $38 \%$ in $\mathrm{HSu}$ and HF animals, respectively, and CSN transection completely restored insulin receptor activity (Fig. 2e). The high-sugar and high-fat diets significantly decreased GLUT4 levels in adipose tissue, by $21 \%$ and $16 \%$, respectively (Fig. $2 \mathrm{~h}$ ), and Akt values by $47 \%$ and $36 \%$, respectively (Fig. 2f). CSN transection overturned the effect of the high-energy diets on adipose tissue levels of both GLUT4 and Akt (Fig. 2f, h). Akt activity decreased significantly, by $45 \%$ and $21 \%$ in $\mathrm{HSu}$ and $\mathrm{HF}$ rats, respectively (Fig. $2 \mathrm{~g}$ ). CSN transection increased Akt phosphorylation by $44 \%$ and $39 \%$ in $\mathrm{HSu}$ and $\mathrm{HF}$ animals, respectively (Fig. 2g). 
Table 1 CSN transection restores plasma insulin and C-peptide levels in HSu and HF rats

\begin{tabular}{|c|c|c|c|c|c|c|}
\hline \multirow[t]{2}{*}{ Variable } & \multicolumn{2}{|l|}{ Control } & \multicolumn{2}{|l|}{$\mathrm{HSu}$} & \multicolumn{2}{|l|}{$\mathrm{HF}$} \\
\hline & $\begin{array}{l}\text { Without CSN } \\
\text { transection }\end{array}$ & $\begin{array}{l}\text { With CSN } \\
\text { transection }\end{array}$ & $\begin{array}{l}\text { Without CSN } \\
\text { transection }\end{array}$ & $\begin{array}{l}\text { With CSN } \\
\text { transection }\end{array}$ & $\begin{array}{l}\text { Without CSN } \\
\text { transection }\end{array}$ & $\begin{array}{l}\text { With CSN } \\
\text { transection }\end{array}$ \\
\hline Insulin (pmol/l) & $341.2 \pm 48.2$ & $363.8 \pm 67.2$ & $760.3 \pm 77.6^{* * * *}$ & $381.3 \pm 56.9^{\dagger \dagger}$ & $750.0 \pm 93.1 * * *$ & $227.6 \pm 68.9^{\dagger \dagger \dagger}$ \\
\hline $\begin{array}{l}\text { C-peptide } \\
\text { (nmol/1) }\end{array}$ & $0.89 \pm 0.13$ & $0.86 \pm 0.12$ & $1.48 \pm 0.21 *$ & $0.73 \pm 0.15^{\dagger}$ & $1.62 \pm 0.29 *$ & $0.80 \pm 0.10^{\dagger \dagger}$ \\
\hline
\end{tabular}

Data are presented as mean \pm SEM

Without CSN transection, $n=6-8$; with CSN transection, $n=8-9$

Two-way ANOVA with Bonferroni multiple comparison tests; ${ }^{*} p<0.05, * * * p<0.001$ vs controls; ${ }^{\dagger} p<0.05,{ }^{\dagger \dagger} p<0.01,{ }^{\dagger \dagger} p<0.001$ with vs without CSN transection

In liver, insulin receptor levels and activity were not altered by either high-energy diets or CSN transection (Fig. 2i, j). In contrast, CSN ablation increased GLUT2 levels in HF animals by $40 \%$, compared with controls (Fig. $2 \mathrm{k}$ ).

\section{CSN transection restores whole-body glucose tolerance, and liver and visceral adipose tissue glucose uptake in $\mathrm{HF}$ animals}

The effect of chronic bilateral CSN resection on glucose uptake was evaluated using 2-deoxy $\left[{ }^{3} \mathrm{H}\right]$ glucose IVGTT. For these experiments, the HF model was selected because of its obesity phenotype and was compared with controls. Figure 3 shows similar IVGTT results to those observed in Fig. 1 for the ITT, as shown by the significant increase in the area under the glucose excursion curve in this group (controls, $1.6 \times 10^{7} \pm 6.5 \times 10^{5}$; HF rats, $2.1 \times 10^{7} \pm 1.7 \times 10^{6}$, Fig. 3b). Three weeks after CSN transection, glucose tolerance was restored in HF animals, shown by a decrease in AUC to values similar to those of control rats that had undergone the sham procedure (AUC HF with transected CSN, $1.6 \times 10^{7} \pm 7.1 \times 10^{5}$ ).

After 6 weeks of the high-fat diet, the glucose metabolic index $\left(\operatorname{Rg}^{\prime}\right)$, which evaluates glucose uptake, decreased by $42 \%$ and by $43 \%$ for the liver and pancreas, respectively. Glucose uptake by the soleus and gastrocnemius muscles did not significantly change, compared with controls (Fig. 3c). CSN transection produced a significant increase of $43 \%$ in 2-deoxy $\left[{ }^{3} \mathrm{H}\right]$ glucose uptake by the liver compared with HFD animals with an intact CSN. However, no change in glucose uptake was observed for the pancreas, soleus or gastrocnemius tissues ( $\mathrm{Rg}^{\prime}$ of liver: $\mathrm{HF}$ without $\mathrm{CSN}$ transection, $3.15 \pm 0.33 \mathrm{mmol}[\mathrm{mg} \text { tissue }]^{-1} \mathrm{~min}^{-1}$; HF with CSN transection, $4.50 \pm 0.45 \mathrm{mmol}[\mathrm{mg} \text { tissue }]^{-1} \mathrm{~min}^{-1}$; Fig. 3c). Finally, in visceral adipose tissue, 6 weeks of the high-fat diet decreased glucose uptake by $45 \%$ compared with the control group, and this effect was completely restored by CSN transection ( $\mathrm{Rg}^{\prime}$ of perienteric adipose tissue: controls without CSN transection, $1.46 \pm 0.13 \mathrm{mmol}$ [mg tissue $]^{-1} \mathrm{~min}^{-1}$; HF without CSN transection, 0.81 $\pm 0.16 \mathrm{mmol}[\mathrm{mg} \text { tissue }]^{-1} \mathrm{~min}^{-1}$; HF with CSN transection, $1.44 \pm 0.33 \mathrm{mmol}[\mathrm{mg} \text { tissue }]^{-1} \mathrm{~min}^{-1}$; Fig. $3 \mathrm{~d}$ ). No significant results were observed for epididymal and perinephric adipose tissue (Fig. 3d).

\section{CSN denervation ameliorates lipid profile in animal models of impaired insulin sensitivity}

The HSu and HF animals showed no change in either total cholesterol or LDL-cholesterol (Table 2). In contrast, HDLcholesterol was decreased in HF animals by $28 \%$ and was restored to control values by CSN transection (Table 2). Additionally, the HSu and HF rats had increased triacylglycerol levels by $75 \%$ and $47 \%$, respectively; these values returned to control levels after CSN resection (Table 2).

\section{CSN transection normalises mean arterial pressure, nitric oxide metabolites and sympathetic activity in animal models of impared insulin sensitivity}

In the current study, HSu and HF rats had a 39\% increase in mean arterial pressure. These results are in line with the values previously obtained in our laboratory [5, 13]. Three weeks after CSN resection, mean arterial pressure was fully restored to control levels in both $\mathrm{HSu}(96.7 \pm 11.8 \mathrm{mmHg})$ and $\mathrm{HF}$ $(92.1 \pm 9.6 \mathrm{mmHg}$ ) animals (Fig. 4a).

The effect of CSN resection on serum nitric oxide and its metabolites $\left(\mathrm{NO}+\mathrm{NO}_{3}\right)$ is depicted in Fig. 4b. Although no significant effects were observed in $\mathrm{HSu}$ rats, the HF rats had significantly increased $\mathrm{NO}+\mathrm{NO}_{3}$ levels compared with controls (control, $10.6 \pm 1.1 \mu \mathrm{mol} / \mathrm{l} ; \mathrm{HF}, 21.3 \pm 2.0 \mu \mathrm{mol} / \mathrm{l}$ ), with this effect being completely restored by chronic CSN resection.

Since CB overactivity contributes to the development of IR and hypertension through sympathoadrenal overstimulation [5], we also analysed sympathetic nervous activity using spectral analysis of heart rate variability and via the measurement of circulating and adrenal medullary catecholamines. We observed that sympathetic activity was increased in the animals 
a

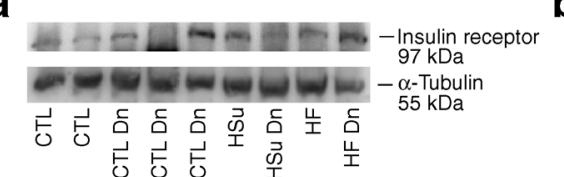

b

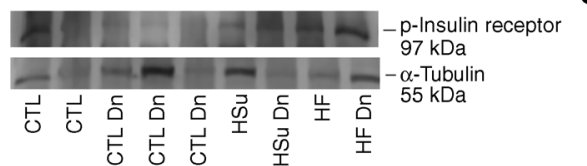

C

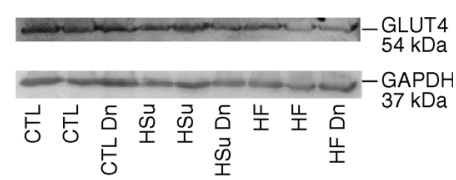

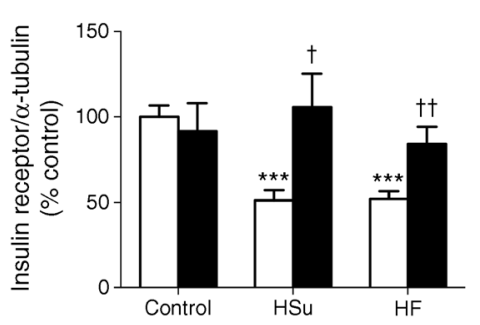

d
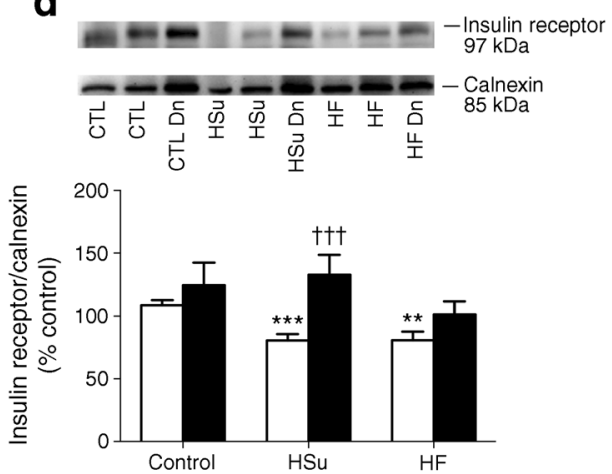

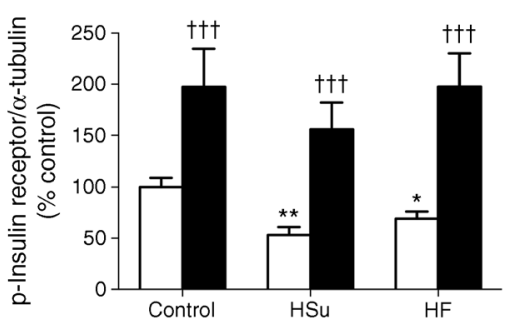

e
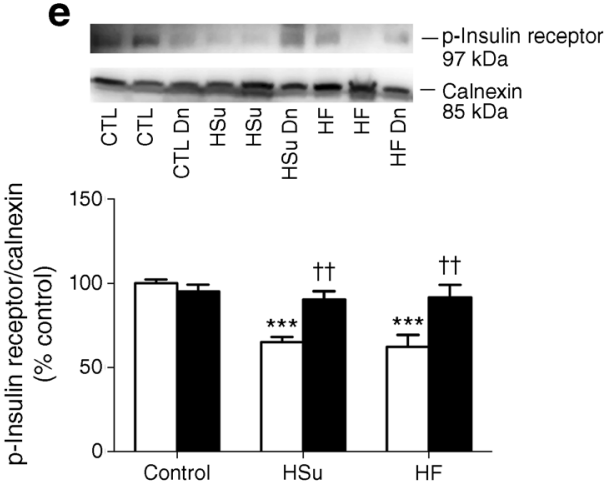
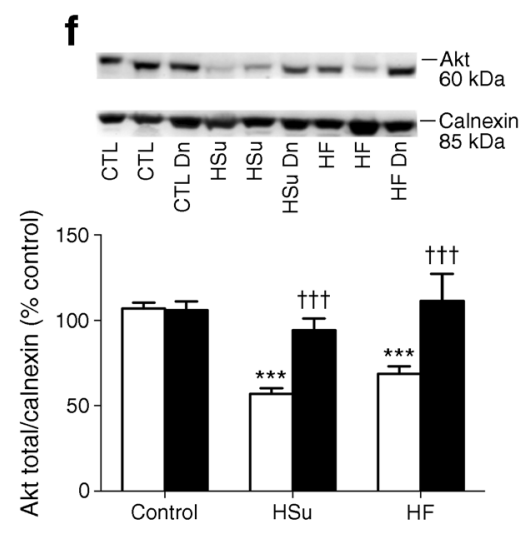

i
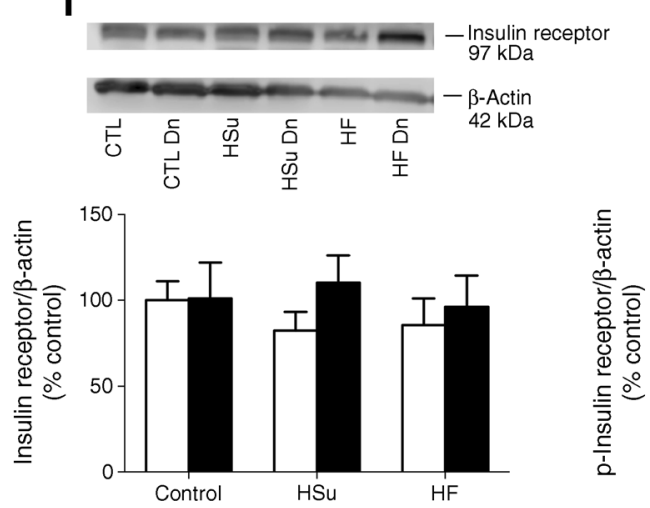

g
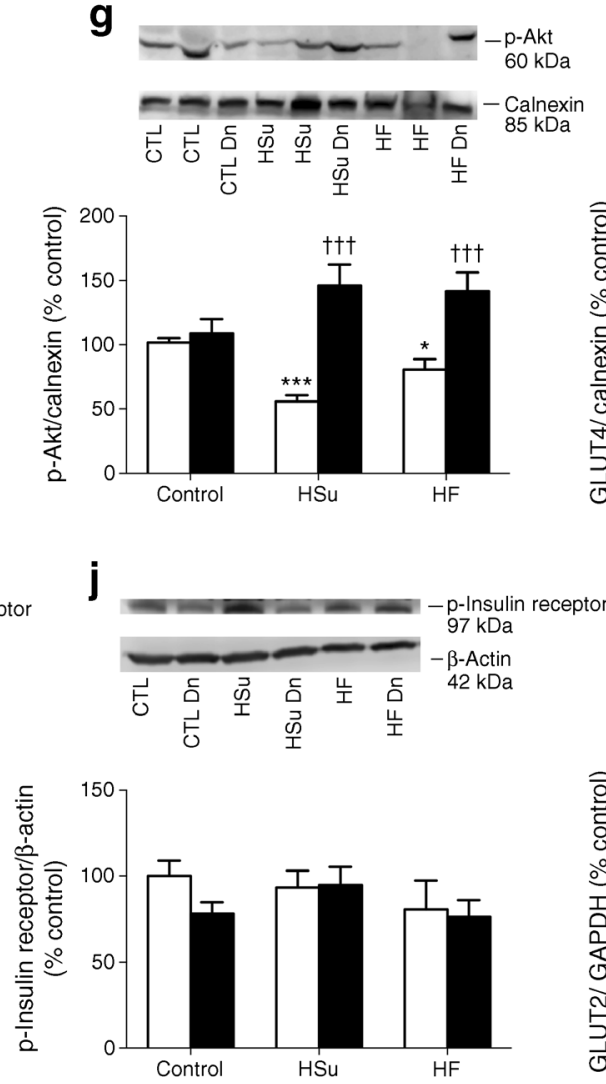

h

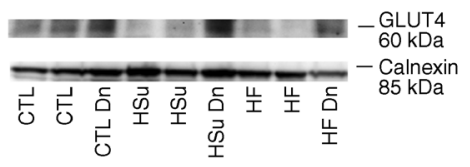

k
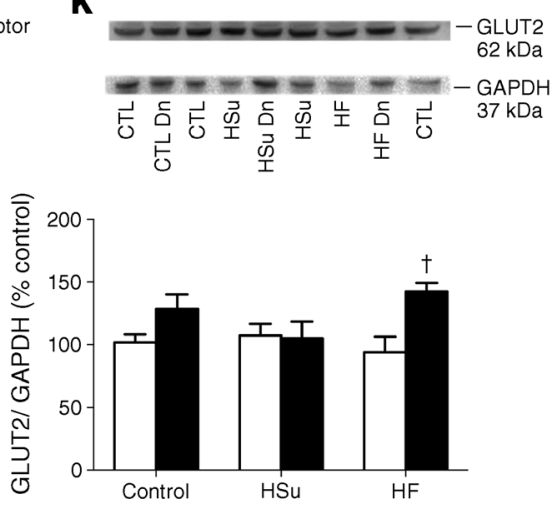
Fig. 2 Effect of chronic CSN resection on level and activity of proteins involved in insulin signalling in (a-c) skeletal muscle, $(\mathbf{d}-\mathbf{h})$ adipose tissue and (i-k) the liver. Average relative (a) insulin receptor levels (97 kDa), (b) insulin receptor phosphorylation $(97 \mathrm{kDa})$, and (c) GLUT4 $(54 \mathrm{kDa})$ immunoreactivity in skeletal muscle from control, $\mathrm{HSu}$ and $\mathrm{HF}$ animals with ( $n=5-6)$ or without $(n=5-10)$ CSN resection. Average relative (d) insulin receptor levels, (e) insulin receptor phosphorylation, (f) Akt levels $(60 \mathrm{kDa}),(\mathbf{g})$ Akt phosphorylation $(60 \mathrm{kDa})$ and (h) GLUT4 immunoreactivity in adipose tissue from control, HSu and HF animals with $(n=5-7)$ or without $(n=7-10)$ CSN resection. Average relative (i) insulin receptor levels, (j) insulin receptor phosphorylation and (k) GLUT2 $(62 \mathrm{kDa})$ immunoreactivity in liver from control, HSu and HF animals with $(n=5-6)$ or without $(n=5-10)$ CSN resection. White bars without CSN denervation; black bars, with CSN denervation. Data are presented as mean $\pm \mathrm{SEM}$. Representative western blots for each protein studied are depicted above the respective bar graphs. Dn, denervated/ transected. Two-way ANOVA with Bonferroni multiple comparison tests; ${ }^{*} p<0.05, * * p<0.01, * * * p<0.001$ vs control; ${ }^{\dagger} p<0.05,{ }^{\dagger \dagger} p<0.01$, ${ }^{\dagger \dagger} p<0.001$ with vs without CSN resection

fed a high-energy diet and that this effect was normalised by CSN transection (see ESM Results and ESM Fig. 1).

\section{Discussion}

We have established that abolition of CB activity may represent a therapeutic strategy for pre-existing metabolic diseases. In $\mathrm{HF}$ and $\mathrm{HSu}$ rats, chronic bilateral CSN transection fully restored insulin action, fasting plasma glucose and insulin levels, blood pressure, and lipid profile to physiological values. It also restored insulin signalling pathways in skeletal muscle and adipose tissue. Additionally, CSN transection improved glucose uptake by the liver and perienteric adipose tissue concomitantly with restoration of autonomic imbalance. Another important observation was that the metabolic improvement induced by CSN surgical ablation was maintained, even when animals were continuously fed high-energy diets.

\section{Effect of CSN transection on whole-body insulin action and insulin secretion}

We have demonstrated that chronic bilateral CSN resection restored insulin action in animal models of impaired insulin sensitivity, an effect that was sustained over time, as demonstrated by improved insulin sensitivity in $\mathrm{HSu}$ animals 11 weeks after the intervention. The time frame of 11 weeks was chosen because the CSN starts to regrow 6 days after being cut and usually completely regenerates after 11-12 weeks [25]. We also evaluated the effect of unilateral CSN resection in HF animals, a procedure that was ineffective in restoring insulin sensitivity in this pathological model. Our results are supported by Fudim et al [26], who demonstrated that the hypotensive effect of unilateral resection of $\mathrm{CB}$ tumours in patients with hypertension diminished over the long term. Moreover, Paton et al [27] also observed that, 12 months after unilateral CB ablation, the significant decrease in blood pressure initially observed was
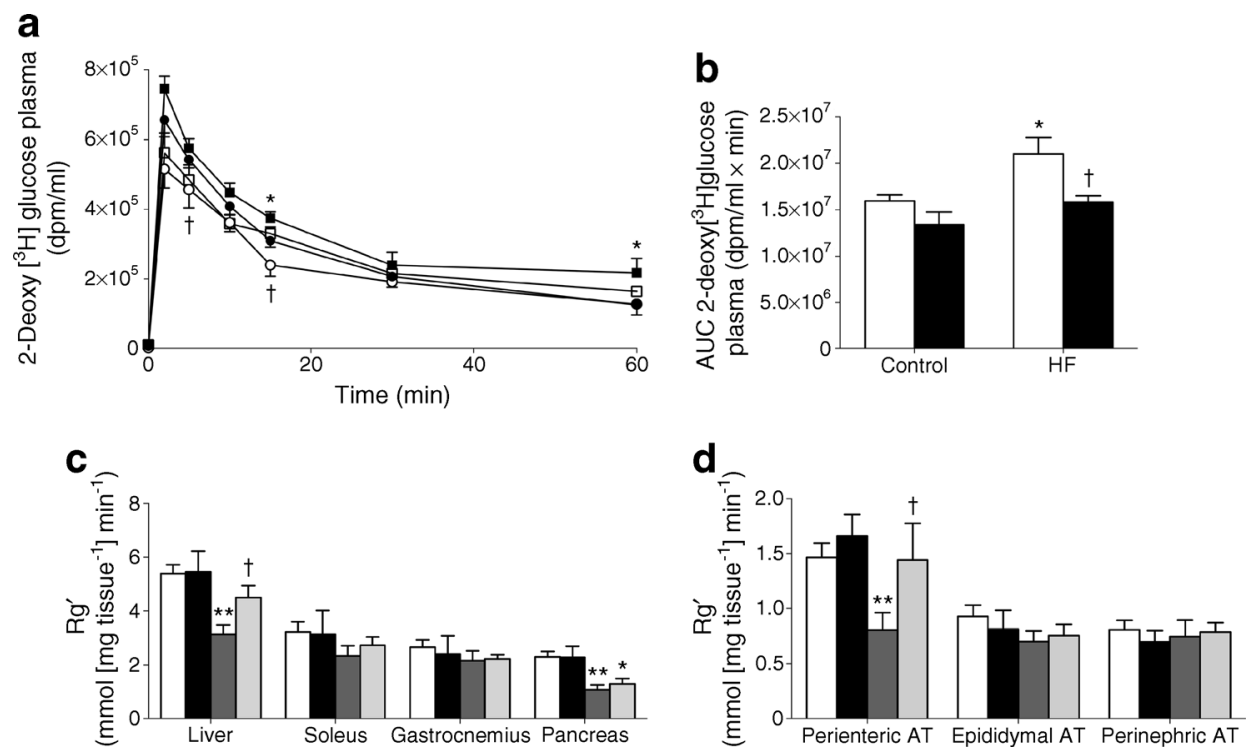

Fig. 3 Chronic bilateral CSN resection restores glucose tolerance via its action on visceral/perienteric adipose tissue and liver glucose uptake in $\mathrm{HF}$ rats. Effect of chronic CSN transection on glucose tolerance after an IVGTT depicted as (a) glucose excursion curves. Black circles, controls without CSN denervation; white circles, controls with CSN denervation; black squares, HF without CSN denervation; white squares, HF with CSN denervation ( $n=8$ for each). (b) AUC obtained from the analysis of glucose excursion curves. White bars, without CSN resection $(n=6-9)$; black bars, with CSN resection $(n=8)$. (c) $\mathrm{Rg}^{\prime}$ values, reflecting glucose uptake in the

liver, soleus, gastrocnemius and pancreas. (d) $\mathrm{Rg}^{\prime}$ values for perienteric, epididymal and perinephric adipose tissue (AT). Evaluation was performed 3 weeks after CSN transection. (c, d) White bars, controls without CSN resection $(n=8)$; black bars, controls with CSN resection $(n=6)$; dark grey bars, HF without CSN resection $(n=8)$; light grey bars, HF with CSN resection $(n=7)$. Data are presented as mean \pm SEM. Two-way ANOVA with Bonferroni multiple comparison tests: ${ }^{*} p<0.05, * * p<0.01$ vs control; ${ }^{\dagger} p<0.05$ with vs without $\mathrm{CSN}$ resection CSN transection 
Table 2 Effect of CSN transection on lipid profile in control, HF and HSu rats

\begin{tabular}{|c|c|c|c|c|c|c|}
\hline \multirow[t]{2}{*}{ Variable } & \multicolumn{2}{|l|}{ Control } & \multicolumn{2}{|l|}{$\mathrm{HSu}$} & \multicolumn{2}{|l|}{$\mathrm{HF}$} \\
\hline & $\begin{array}{l}\text { Without CSN } \\
\text { transection }\end{array}$ & $\begin{array}{l}\text { With CSN } \\
\text { transection }\end{array}$ & $\begin{array}{l}\text { Without CSN } \\
\text { transection }\end{array}$ & $\begin{array}{l}\text { With CSN } \\
\text { transection }\end{array}$ & $\begin{array}{l}\text { Without CSN } \\
\text { transection }\end{array}$ & $\begin{array}{l}\text { With CSN } \\
\text { transection }\end{array}$ \\
\hline $\begin{array}{l}\text { Total cholesterol } \\
(\mathrm{mmol} / \mathrm{l})\end{array}$ & $3.72 \pm 0.20$ & $3.55 \pm 0.26$ & $4.26 \pm 0.22$ & $3.67 \pm 0.12$ & $3.50 \pm 0.15$ & $3.60 \pm 0.15$ \\
\hline $\begin{array}{l}\text { LDL-cholesterol } \\
(\mathrm{mmol} / \mathrm{l})\end{array}$ & $0.38 \pm 0.02$ & $0.41 \pm 0.04$ & $0.38 \pm 0.01$ & $0.38 \pm 0.01$ & $0.33 \pm 0.04$ & $0.30 \pm 0.06$ \\
\hline $\begin{array}{l}\text { HDL-cholesterol } \\
(\mathrm{mmol} / \mathrm{l})\end{array}$ & $1.45 \pm 0.06$ & $1.26 \pm 0.06$ & $1.46 \pm 0.08$ & $1.35 \pm 0.05$ & $1.04 \pm 0.06^{* * *}$ & $1.30 \pm 0.10^{\dagger}$ \\
\hline $\begin{array}{l}\text { Triacylglycerols } \\
(\mathrm{mmol} / \mathrm{l})\end{array}$ & $1.05 \pm 0.12$ & $0.69 \pm 0.09$ & $1.84 \pm 0.21 * * *$ & $0.75 \pm 0.12^{\dagger \dagger \dagger}$ & $1.54 \pm 0.12 *$ & $0.67 \pm 0.18^{\dagger \dagger}$ \\
\hline
\end{tabular}

Data are presented as mean \pm SEM

Without CSN transection, $n=8-9$; with CSN transection, $n=8-10$

Two-way ANOVA with Bonferroni multiple comparison tests; $* p<0.05$, $* * * p<0.001$ vs control; ${ }^{\dagger \dagger} p<0.01,{ }^{\dagger \dagger} p<0.001$ with vs without CSN transection

attenuated. These and our own results corroborate the hypothesis that unilateral denervation is compensated by the remaining $\mathrm{CB}$, counteracting the beneficial effect of denervation. This suggests that bilateral denervation is needed to achieve a sustained effect on insulin action and glucose metabolism.

Fasting plasma insulin and glucose were also normalised by bilateral CSN transection. These effects were accompanied by a re-establishment of endogenous insulin secretion, since we observed normalisation of both insulin and C-peptide levels. These results may be either an indirect consequence of improved peripheral insulin sensitivity or a direct effect of the CBs on neurally mediated insulin secretion. Koyama et al have previously demonstrated that $\mathrm{CB}$ ablation reduces basal glucagon secretion, and that this surgical approach may also affect insulin secretion [3,28].

\section{Effect of CSN transection on glucose homeostasis}

Bilateral CSN transection improved insulin signalling in skeletal muscle in the HF and HSu animal models tested; it fully

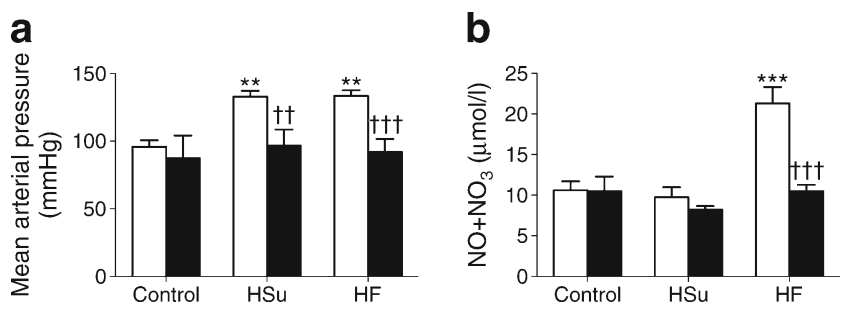

Fig. 4 Effect of CSN transection on (a) mean arterial pressure and (b) plasma $\mathrm{NO}+\mathrm{NO}_{3}$ in control, $\mathrm{HSu}$ and $\mathrm{HF}$ animals. Blood pressure and $\mathrm{NO}+\mathrm{NO}_{3}$ measurement was performed 3 weeks after chronic $\mathrm{CSN}$ denervation. White bars, without CSN resection ( $n=8-9)$; black bars, with CSN resection $(n=6-8)$. Data are presented as mean \pm SEM. Two-way ANOVA with Bonferroni multiple comparison tests: $* * p<0.01, * * * p<0.001$ vs control; ${ }^{\dagger} p<0.01,{ }^{\dagger \dagger} p<0.001$ with vs without CSN transection restored insulin receptor and phosphorylated insulin receptor levels in both animal models, and increased GLUT4 levels in HSu animals. HF animals did not exhibit decreased GLUT4 expression in skeletal muscle, and CSN surgical ablation did not alter these values. The latter result is not unique as GLUT4 protein content is known to be normal in muscle from insulinresistant individuals; however, insulin-stimulated GLUT4 translocation is impaired in these patients [29]. Accordingly, despite the improvement in insulin receptor levels (phosphorylated and non-phosphorylated) in the skeletal muscle of HF animals after surgery, we did not observe significant changes in 2-deoxy $\left[{ }^{3} \mathrm{H}\right]$ glucose uptake in either soleus or gastrocnemius muscles, which may be explained by a decrease in insulin-stimulated GLUT4 translocation in the muscle of HF animals. Nevertheless, this hypothesis remains speculative since we only assessed total GLUT4 levels and did not investigate translocation of this molecule. As expected, high-energy diets decreased the expression levels of insulin receptor, GLUT4 and Akt, as well as the phosphorylation of the insulin receptor and Akt in perienteric adipose tissue. Marked impairments in the insulin signalling cascade have been described in fat cells from both animal models and in patients with type 2 diabetes [20, 30-32]. In both $\mathrm{HSu}$ and HF rats, chronic CSN transection restored perienteric adipose tissue levels of Akt, phosphorylated Akt and GLUT4, so that they were similar to controls. This improvement in insulin receptor activation and protein levels in adipose tissue was accompanied by an increase in 2-deoxy $\left[{ }^{3} \mathrm{H}\right]$ glucose uptake in the perienteric adipose tissue of HF rats. 2-Deoxy $\left[{ }^{3} \mathrm{H}\right]$ glucose uptake assays were performed in the HF model, and not the HSu rats, due to their obesity phenotype - resembling the metabolic syndrome and diabetes in humans - and also because the adipose tissue in these rat models was most affected by bilateral CSN transection. These results strongly suggest that visceral/perienteric fat is one of the tissues under the metabolic control of $\mathrm{CBs}$, and that CSN 
transection improves insulin-stimulated glucose disposal in adipose tissue.

There were no significant changes in hepatic levels of insulin receptors and their phosphorylation in HF or HSu rats. However, GLUT2 levels and $\mathrm{Rg}^{\prime}$ were significantly increased in the liver of HF rats after surgery. It is conceivable that this may also contribute to the improvements in whole-body insulin action mediated by CSN transection. Cherrington's group [33] has shown that both sympathetic and nitrergic innervation of the liver exerts tonic repression of hepatic glucose uptake under feeding conditions. The consumption of high-fat and high-fructose diets impairs net hepatic glucose uptake and glycogen storage, and reduces glucokinase protein level and activity [34]. According to Cherrington's work, a tonic inhibition of hepatic sympathetic innervation improves hepatic glucose uptake, storage and output, leading to improved glucose homeostasis. This may be achieved by the inhibition of CB activity since this organ is directly linked to the sympathetic nervous system and has also been shown to be involved in a diminished counterregulatory response, by impacting the release of counterregulatory hormones, such as glucagon [28]. According to our results, one of the mechanisms by which sympathetic blockade increases hepatic glucose uptake appears to be an increase in GLUT2 levels in hepatocytes, and although we did not assess this in our work, an increase in glucokinase activity may also be involved. The dynamic IVGTT profiles observed indicate that CSN transection improves first-phase insulin secretion in both control and HF animals by lowering the maximum glucose concentration reached during the test. Additionally, the rapid uptake of glucose by the peripheral tissues may explain the steeper slope observed for the descending phase of the curve [35].

\section{Effect of CSN transection on haemodynamic homeostasis}

Mean arterial pressure was fully restored to control levels in $\mathrm{HSu}$ and $\mathrm{HF}$ animals. This is in accordance with a recent proposal that carotid glomectomy may represent a powerful way to prevent excessive sympathetic discharge in diseases such as hypertension $[36,37]$. Our results also show that $\mathrm{CSN}$ transection normalises $\mathrm{NO}+\mathrm{NO}_{3}$ in $\mathrm{HF}$ animals. Rats fed a high-fat diet are known to have higher levels of inducible nitric oxide synthase and increased inflammatory biomarkers [38]. Therefore, CSN resection ameliorates endothelial function, restoring $\mathrm{NO}+\mathrm{NO}_{3}$ levels to values similar to control. This may result from improved glucose and lipid homeostasis [38], as well as from decreased mean arterial pressure and restoration of endothelial function. One of the concerns related to the surgical approach of CSN surgical ablation is that, as well as chemoreceptor activity, CSN carries baroreceptor information. It is well documented that resection of the baroreceptors can cause short-term fluctuations in blood pressure since baroreceptors play a major role in short-term regulation of blood pressure [39, 40]. These short-term fluctuations can be compensated in the long term [40,41], either by the central nervous system, by renal fluid volume-adjusting mechanisms [39] or by the aortic bodies, as evidenced by recent studies that have shown that the arterial baroreflex is a long-term regulator of blood pressure [42-44]. These long-term adjustments of the arterial baroreflex may explain the significant decrease in blood pressure after CSN transection that was observed in the present study.

\section{Effect of CSN transection on lipid homeostasis}

Increased plasma triacylglycerols and LDL-cholesterol, together with low HDL-cholesterol levels are central pathophysiological features of metabolic diseases. We observed that CSN denervation fully restored plasma triacylglycerols to control values and significantly increased HDL-cholesterol in the HF model. The major sources of triacylglycerol secretion by the liver are fatty acids from adipose tissue (released by lipolysis) or in the form of remnant lipoproteins, and hepatic de novo lipogenesis, which are all abnormally increased in IR. Whether the improved lipid profile observed in HF rats was indirectly caused by enhancement of insulin sensitivity or by the direct action of CSN-controlled sympathetic efferent pathways on the liver, as previously suggested $[45,46]$, remains to be clarified.

\section{Concluding remarks}

Bilateral abolition of CB activity restores glucohomeostasis, lipohomeostasis and haemodynamic homeostasis in animal models of pre-established metabolic disease. These effects are sustained for at least 11 weeks after surgery. Additionally, the mechanism behind the repair of glucohomeostasis and lipohomeostasis involves an improvement in glucose uptake by the liver and re-establishment of glucose uptake by perienteric adipose tissue, concomitantly with an improvement in autonomic function. Our data represent proof of principle that abolition of CB activity reverses core features of metabolic disease, and highlight the importance of developing strategies to reduce neural activity in CBs.

Data availability All data generated or analysed during this study are included in this published article (and its supplementary information files).

Funding This study was supported by the Portuguese Foundation for Science and Technology (FCT), grants EXPL/NEU-SCC/2183 and Pest-C/SAU/UI3282/2011, grant BFU2015-70616-R (MINECO/FEDER, UE) (Spain) and grant CIBER CB06/06/0050 from the Institute of Health Carlos III (Spain). JFS and MJR are supported by PhD Grants from FCT, PD/BD/105890/2014 and SFR/BD/ $88983 / 2012$, respectively. 
Duality of interest The authors declare that there is no duality of interest associated with this manuscript.

Contribution statement SVC is the guarantor of this work, had full access to all the data and takes full responsibility for integrity of the data and accuracy of data analysis. SVC, JFS, MJR, BFM, EO, AO, JC, CRF, MPG, TR, RS, PM and RF-P made substantial contributions to conception and design, acquisition of data, or analysis and interpretation of data. All authors have drafted the article or revised it critically for important intellectual content. All authors approved the final version of the manuscript.

\section{References}

1. Gonzalez C, Almaraz L, Obeso A, Rigual R (1994) Carotid body chemoreceptors: from natural stimuli to sensory discharges. Physiol Rev 74:829-898

2. Marshall JM (1994) Peripheral chemoreceptors and cardiovascular regulation. Physiol Rev 74:543-594

3. Koyama Y, Coker RH, Stone EE et al (2000) Evidence that carotid bodies play an important role in glucoregulation in vivo. Diabetes 49:1434-1442

4. Wehrwein EA, Basu R, Basu A, Curry TB, Rizza RA, Joyner MJ (2010) Hyperoxia blunts counterregulation during hypoglycaemia in humans: possible role for the role of carotid bodies? J Physiol 588:4593-4601

5. Ribeiro MJ, Sacramento JF, Gonzalez C, Guarino MP, Monteiro EC, Conde SV (2013) Carotid body denervation prevents the development of insulin resistance and hypertension induced by hypercaloric diets. Diabetes 62:2905-2916

6. Vera-Cruz P, Guerreiro F, Ribeiro MJ, Guarino MP, Conde SV (2015) Hyperbaric oxygen therapy improves glucose homeostasis in type 2 diabetes patients: a likely involvement of the carotid bodies. In: Peers C, Kumar P, Wyatt CN, Gauda E, Nurse CA, Prabhakar N (eds) Advances in experimental medicine and biology - arterial chemoreceptors in physiology and pathophysiology. Springer International Publishing, Switzerland, pp 221-225

7. Desola J, Crespo A, Garcia A, Salinas A, Sala J, Sánchez U (1998) Indicaciones y contraindicaciones de la oxigenoterapia hiperbárica. JANO/Medicina LIV 1260:5-11

8. Ekanayake L, Doolette DJ (2001) Effects of hyperbaric oxygen treatment on blood sugar levels and insulin levels in diabetics. SPUMS 31:16-20

9. Karadurmus N, Sahin M, Tasci C et al (2010) Potential benefits of hyperbaric oxygen therapy on atherosclerosis and glycemic control in patients with diabetic foot. Endokrybol Pol 61:275-279

10. Wilkinson D, Chapman IM, Heilbronn LK (2012) Hyperbaric oxygen therapy improves peripheral insulin sensitivity in humans. Diabet Med 29:986-989

11. Peleg RK, Fishlev G, Bechor Y et al (2013) Effects of hyperbaric oxygen on blood glucose levels in patients with diabetes mellitus, stroke or traumatic injury and healthy volunteers: a prospective, crossover, controlled trial. Diving Hyperb Med 43:218-221

12. Ribeiro RT, Lautt WW, Legare DJ, Macedo MP (2005) Insulin resistance induced by sucrose feeding in rats is due to an impairment of the hepatic parasympathetic nerves. Diabetologia 48: 976-983

13. Conde SV, Nunes da Silva T, Gonzalez C, Mota Carmo M, Monteiro EC, Guarino MP (2012) Chronic caffeine intake decreases circulating catecholamines and prevents diet-induced insulin resistance and hypertension in rats. Br J Nutr 107:86-95
14. Shearer J, Severson DL, Su L, Belardinelli L, Dhalla AK (2009) Partial A1 adenosine receptor agonist regulates cardiac substrate utilization in insulin-resistant rats in vivo. J Pharmacol Exp Ther 328:306-311

15. Panchal SK, Brown L (2011) Rodent models for metabolic syndrome research. J Biomed Biotechnol 2011:351982

16. Monteiro EC, Ribeiro JA (1989) Inhibition by 1, 3-dipropyl 8 (psulfophenyl) xanthine of the respiratory stimulation induced by common carotid occlusions in rats. Life Sci 45:939-945

17. Guarino MP, Ribeiro MJ, Sacramento JS, Conde SV (2013) Chronic caffeine intake reverses age-induced insulin resistance in the rat: effect on skeletal muscle Glut4 transporters and AMPK activity. Age 35:1755-1765

18. Sacramento JF, Ribeiro MJ, Rodrigues T et al (2016) Insulin resistance is associated with tissue-specific regulation of HIF- $1 \alpha$ and HIF- $2 \alpha$ during mild chronic intermittent hypoxia. Respir Physiol Neurobiol 228:30-8

19. Kraegen EW, James DE, Jenkins AB, Chisholm DJ (1985) Doseresponse curves for in vivo insulin sensitivity in individual tissues in rats. Am J Physiol 248:E353-E362

20. Matafome P, Rodrigues T, Pereira A et al (2014) Long-term globular adiponectin administration improves adipose tissue dysmetabolism in high-fat diet-fed Wistar rats. Arch Physiol Biochem 120:147-157

21. Ori Z, Monir G, Weiss J, Sahyouni XN, Singer DH (1992) Heart rate variability: frequency domain analysis. Cardiol Clin 10: 499-538

22. Fonseca-Pinto R (2011) A new tool for nonstationary and nonlinear signals: the Hilbert-Huang transform in biomedical applications, biomedical engineering. In: Laskovski A (ed.) Trends in electronics, communications and software InTech, pp 481-504. ISBN: 978953-307-475-7

23. Thireau J, Zhang BL, Poisson D, Babuty D (2008) Heart rate variability in mice: a theoretical and practical guide. Exp Physiol 93: 83-94

24. Herrington LP (1940) The heat regulation of small laboratory animals at various environmental temperatures. Am J Physiol 129: 123-139

25. Zapata P, Stensaas LJ, Eyzaguirre C (1976) Axon regeneration following a lesion of the carotid nerve: electrophysiological and ultrastructural observations. Brain Res 113:235-253

26. Fudim M, Groom KL, Laffer CL, Netterville JL, Robertson D, Elijovich F (2015) Effects of carotid body tumor resection on the blood pressure of essential hypertensive patients. J Am Soc Hypertens 9:435-442

27. Paton JFR (2015) Hypertension - a visceral problem. Autonomic Neurosci: Basic Clin 192:16

28. Koyama Y, Coker RH, Denny JC et al (2001) Role of carotid bodies in control of the neuroendocrine response to exercise. Am J Physiol Endocrinol Metab 281:E742-E748

29. Garvey WT, Maianu L, Zhu JH, Brechtel-Hook G, Wallace P, Baron ADJ (1998) Evidence for defects in the trafficking and translocation of GLUT4 glucose transporters in skeletal muscle as a cause of human insulin resistance. Clin Invest 101:2377-2386

30. Rondinone CM, Wang LM, Lonnroth P, Wesslau C, Pierce JH, Smith U (1997) Insulin receptor substrate (IRS) 1 is reduced and IRS-2 is the main docking protein for phosphatidylinositol 3-kinase in adipocytes from subjects with non-insulin-dependent diabetes mellitus. Proc Natl Acad Sci U S A 94:4171-4175

31. Smith U (2002) Impaired ('diabetic') insulin signaling and action occur in fat cells long before glucose intolerance - is insulin resistance initiated in the adipose tissue? Int J Obes Relat Metab Disord 26:897-904

32. Matafome P, Rodrigues T, Seica R (2015) Glycation and hypoxia: two key factors for adipose tissue dysfunction. Curr Med Chem 22: 2417-2437 
33. Moore MC, Coate KC, Winnick JJ, An Z, Cherrington AD (2012) Regulation of hepatic glucose uptake and storage in vivo. Adv Nutr 3:286-294

34. Coate KC, Kraft G, Lautz M, Smith M, Neal DW, Cherrington AD (2011) A high-fat, high-fructose diet accelerates nutrient absorption and impairs net hepatic glucose uptake in response to a mixed meal in partially pancreatectomized dogs. J Nutr 141:1643-1651

35. Bergman RN, Finegood DT, Ader M (1985) Assessment of insulin sensitivity in vivo. Endocr Rev 6:45-86

36. Paton JF, Sobotka PA, Fudim M et al (2013) The carotid body as a therapeutic target for the treatment of sympathetically mediated diseases. Hypertension 61:5-13

37. Paton JF, Ratcliffe L, Hering D, Wolf J, Sobotka PA, Narkiewicz K (2013) Revelations about carotid body function through its pathological role in resistant hypertension. Curr Hypertens Rep 15:273-280

38. Stanimirovic J, Obradovic M, Jovanovic A et al (2016) A high fat diet induces sex-specific differences in hepatic lipid metabolism and nitrite/nitrate in rats. Nitric Oxide 54:51-59

39. Cowley AW Jr, Liard JF, Guyton AC (1973) Role of baroreceptor reflex in daily control of arterial blood pressure and other variables in dogs. Circ Res 32:564-576
40. Norman RA Jr, Coleman TG, Dent AC (1981) Continuous monitoring of arterial pressure indicates sinoaortic denervated rats are not hypertensive. Hypertension 3:119-125

41. Irigoyen MC, Moreira ED, Ida F, Pires M, Cestari IA, Krieger EM (1995) Changes of renal sympathetic activity in acute and chronic conscious sinoaortic denervated rats. Hypertension 26:1111-1116

42. Lohmeier TE, Iliescu R (2015) The baroreflex as a long-term controller of arterial pressure. Physiology 30:148-158

43. Lohmeier TE, Lohmeier JR, Warren S, May PJ, Cunningham JT (2002) Sustained activation of the central baroreceptor pathway in angiotensin hypertension. Hypertension 39:550-556

44. Zoccal DB, Bonagamba LGH, Paton JFR, Machado BH (2009) Sympathetic mediated hypertension of awake juvenile rats submitted to chronic intermittent hypoxia is not linked to baroreflex dysfunction. Exp Physiol 94:972-983

45. Bruinstroop E, Eliveld J, Foppen E, Busker S, Ackermans MT, Fliers E, Kalsbeek A (2015) Hepatic denervation and dyslipidemia in obese Zucker (fa/fa) rats. Int J Obes 39:1655-1658

46. O'Meara NM, Devery RA, Owens D, Collins PB, Johnson AH, Tomkin GH (1992) Alterations in cellular cholesterol metabolism following administration of 6-hydroxydopamine to rabbits. Br J Pharmacol 105:495-499 